\title{
Synthesis of Novel Azophenylbenzotriazole and Its Application as Anode Materials for Lithium Ion Batteries
}

Shao-hui Sun, Li-ping Duan, Yang-yan Tang, Jun-ming Guo, Xian-hong Ai, Ming-wu Xiang, Rui Wang ${ }^{1, *}$

Yunnan Minzu University, School of Chemistry and Environment, Kunming650000, China

*E-mail: chem503@126.com

doi: $10.20964 / 2019.10 .49$

Received: 4 June 2019 / Accepted: 7 August 2019 / Published: 30 August 2019

The substitution of renewable organic electrodes for environmentally unfriendly inorganic electrodes is a pivotal link in the development of lithium-ion batteries (LiBs) for large-scale energy storage. Here, we report a new type of organic electrode material based on azophenyl and benzotriazolyl (BTA) groups for LiBs. In view of the easy formation of $\mathrm{Cu}$-BTA complexes in the interface of the copper current collector of LiBs anode, we synthesized azophenylalkylbenzotriazoles, and studied their electrochemical behavior and reaction mechanism as organic electrode materials in LiBs. The synthesized azophenylalkylbenzotriazoles showed the high reversible capacity up to $365.8 \mathrm{mAhg}^{-1}$ at $25 \mathrm{mAg}^{-1}$ of current density.

Keywords: azobenzene; electrode material; copper foil; lithium storage performance; electrochemical performance

\section{$\underline{\text { FULL TEXT }}$}

(C) 2019 The Authors. Published by ESG (www.electrochemsci.org). This article is an open access article distributed under the terms and conditions of the Creative Commons Attribution license (http://creativecommons.org/licenses/by/4.0/). 